\title{
Epitheliocystis associated with massive mortalities of cultured lake trout Salvelinus namaycush
}

\author{
Terence M. Bradley ${ }^{1}$, Christian E. Newcomer ${ }^{2, *}$, Kathleen O. Maxwell ${ }^{2}$
}

${ }^{1}$ Department of Fisheries, Animal and Veterinary Sciences, University of Rhode Island, Kingston, Rhode Island 02881-0804, USA

${ }^{2}$ Division of Comparative Medicine, Massachusetts Institute of Technology, Cambridge, Massachusetts 02139, USA

\begin{abstract}
The etiological agent of epitheliocystis in lake trout Salvelinus namaycush at 2 hatcheries (A and B) in the United States was investigated utilizing light, immunofluorescence, and transmission electron microscopy. Branchial inclusions observed in fish at Hatchery A were dispersed at the base of, and randomly along, the secondary lamellae. They included epithelial hyperplasia and hypertrophy, and diffuse lamellar edema and fusion. In fish at Hatchery B the branchial inclusions were located predominantly on the primary lamellae. Pathological alterations were less severe, and were characterized primarily by focal lesions of epithelial hypertrophy. The epitheliocystis particles within the branchial inclusions of fish at both hatcheries exhibited typical chlamydia morphology, size, and developmental stages. A form uncharacteristic of chlamydia was also observed. In addition, a nonchlamydia-like agent was found in branchial tissue of fish at Hatchery B. Immunofluorescent staining of infected branchial tissue with a monoclonal antibody to an antigen specific for the chlamydia genus indicated that the agents lack the lipopolysaccharide common to all known Chlamydia species. Attempts to isolate the agents in McCoy and epithelioma papillosum cyprini (EPC) cell culture systems optimized for chlamydial growth were unsuccessful, possibly due to the poor condition of tissue samples. Massive mortalities of lake trout observed at the 2 hatcheries were associated with the epitheliocystis infections. Investigations in other laboratories failed to reveal the presence of other agents (viruses, bacteria, fungi, ectoparasites) or suboptimal conditions in water quality that might account for the mortalities. The branchial and systemic lesions observed in fish during epizootics are consonant with findings for several epitheliocystis agents and for chlamydia-like agents in other fish species.
\end{abstract}

\section{INTRODUCTION}

Epitheliocystis has been reported worldwide in numerous species of teleost fishes (Hoffman et al. 1969, Wolke et al. 1970, Zachery \& Paperna 1977, Paperna et al. 1978, Paperna \& Baudin-Laurencin 1979, Paperna \& Sabnai 1980, Molnar \& Boros 1981, Paperna et al. 1981, Morrison \& Shum 1983, Zimmer et al. 1984, Miyazaki et al. 1986). However, to date it has been reported in only one salmonid species, the anadromous steelhead trout Salmo gairdneri (Rourke et al. 1984).

Epitheliocystis infection is characterized by the development of variable sized inclusion bodies (cysts) in the branchial epithelium, and in some cases, in the

\footnotetext{
- Present address: Department of Comparative Medicine, Tufts University School of Veterinary Medicine, Boston, Massachusetts 02111, USA
}

mitochondria-rich chloride cells (Paperna et al. 1981, Paperna \& Alves DeMatos 1984). Infection of skin epithelial cells has also been documented (Hoffman et al. 1969). Epitheliocystis infections have been reported as either benign or proliferative, depending on the agent and the host species. Pathological alterations of the gill attributed to epitheliocystis include hyperplasia, hypertrophy, cell and organelle degeneration, and vascular occlusion (Hoffman et al. 1969, Wolke et al. 1970, Paperna 1977, Paperna \& Sabnai 1980, Rourke et al. 1984). However, the pathogenicity and possibility of systemic involvement have not been well documented.

Histological investigations indicate that the morphology and branchial location of the inclusion bodies or 'cysts' may vary between host species. Ultrastructural studies of epitheliocystis have demonstrated that several prokaryotic organisms are involved in this condi- 
tion (Hoffman et al. 1969, Wolke et al. 1970, Paperna 1977, Paperna et al. 1978, Rourke et al. 1984, Miyazaki et al. 1986). However, definitive taxonomic classification is lacking and investigators have classified the various etiologic agents as either rickettsia- or chlamydia-like.

In the present study, we investigated the morphology and ultrastructure of causative agents of epitheliocystis in lake trout Salvelinus namaycush, previously unreported as a host species. The role of these agents in massive mortalities of juvenile lake trout at 2 hatcheries (A and B) was examined. Immunofluorescence studies of the agents and the results of attempts at isolating the agents are presented.

\section{MATERIALS AND METHODS}

Branchial tissue samples were collected from March to May from moribund and healthy under-yearling and from yearling juvenile lake trout Salvelinus namaycush, at 2 hatcheries in the Great Lakes region of the United States. Additional organs from a limited number of fish were also collected during this period. Tissues for light and immunofluorescence microscopy were fixed in $10 \%$ neutral buffered formalin; $6 \mu \mathrm{m}$ sections from paraffin-embedded tissue were stained either with hematoxylin and eosin or Giemsa, or were stored for later examination by immunofluorescence microscopy.

Samples for ultrastructural examination were fixed in $2.0 \%$ paraformaldehyde and $2.5 \%$ glutaraldehyde in $0.1 M$ cacodylate buffer (Karnovsky 1965) overnight at $4{ }^{\circ} \mathrm{C}$ and then rinsed for $24 \mathrm{~h}$ in cold $0.1 \mathrm{M}$ cacodylate buffer. Fixed samples were post-fixed in $1.0 \%$ osmium tetroxide for 3 to $5 \mathrm{~h}$, dehydrated in an acetone series, and infiltrated and embedded in low viscosity resin (Spurr 1969). Ultrathin silver-gold (60 to $90 \mathrm{~nm}$ ) sections were prepared with a Porter Blum MT-2 ultramicrotome, stained with uranyl acetate and lead citrate (Reynolds 1963), and examined with a Hitachi HS-9 transmission electron microscope.

For immunofluorescence microscopy, formalin-fixed tissue sections were stained with a fluorescein isothiocyanate(FITC)-conjugated monoclonal antibody prepared against the chlamydia genus-specific antigen (Bartels Immunodiagnostic Supplies Inc., Bellevue, Washington, USA). Details of the technique have already been described (Swoveland \& Johnson 1979, Olufemi 1986). Positive and negative histologic controls were included also to ensure the retention of specific immunoreactivity of chlamydial antigen in the processed tissues. Branchial tissue from uninfected fish served as negative controls, and formalin-fixed liver tissue from the African clawed frog Xenopus laevis, infected with Chlamydia psittaci (Wilcke et al. 1983), was utilized as a positive control. Incident light, phasecontrast, and fluorescence microscopy were conducted on a Zeiss microscope.

Branchial tissue for isolation attempts was placed in a $0.2 \mathrm{M}$ sucrose phosphate buffer (2SP) containing $10 \mu \mathrm{g}$ $\mathrm{ml}^{-1}$ gentamicin, $10 \mu \mathrm{g} \mathrm{ml}^{-1}$ vancomycin, and $2 \mu \mathrm{g} \mathrm{ml}^{-1}$ fungizone (Spencer \& Johnson 1983), and transported to the laboratory on ice. Samples were stored at $-70{ }^{\circ} \mathrm{C}$ until the isolation attempts were made. Tissue homogenates were prepared at approximately 1:10 (w/ v) and the homogenates were clarified by low speed centrifugation. The supernatant was utilized for inoculation of coverslip monolayers of epithelioma papillosum cyprini (EPC) and McCoy cells grown in glass vials and treated to enhance the isolation of chlamydial organisms utilizing the methods of Ripa \& March (1977). Branchial homogenates from fish at Hatchery A were inoculated on both McCoy and EPC cells, while those from Hatchery B were inoculated on McCoy cells only.

\section{RESULTS}

\section{Epizootics}

During the period of sample collection at Hatchery A, more than $95 \%$ of the juvenile lake trout population, which consisted of more than 1 million individuals, died. Epizootics at Hatchery B resulted in mortalities of approximately $15 \%$ of a population of more than 100000 lake trout.

\section{Histopathology}

The branchial inclusions in the fish from Hatchery A varied in size from 9 to $15 \mu \mathrm{m}$ in diameter and contained numerous densely packed coccoidal basophilic particles (Fig. 1). The inclusions were distributed randomly along the secondary lamellae and several were noted at the base of the lamellae. Branchial inclusions in the fish at Hatchery B were observed predominantly in the interlamellar region and had a size range and morphology similar to those of the fish at Hatchery A (Fig. 2).

Extensive gill lesions were noted in the fish from Hatchery A. Marked epithelial hyperplasia and hypertrophy were present throughout the primary and secondary lamellae whether visibly infected or not (Fig. 1). Inclusions at the base of the secondary lamellae were associated with marked diffuse edema and epithelial hypertrophy and hyperplasia. In addition, a generalized thickening of the secondary lamellae and the accumulation of mucus in the interlamellar regions 


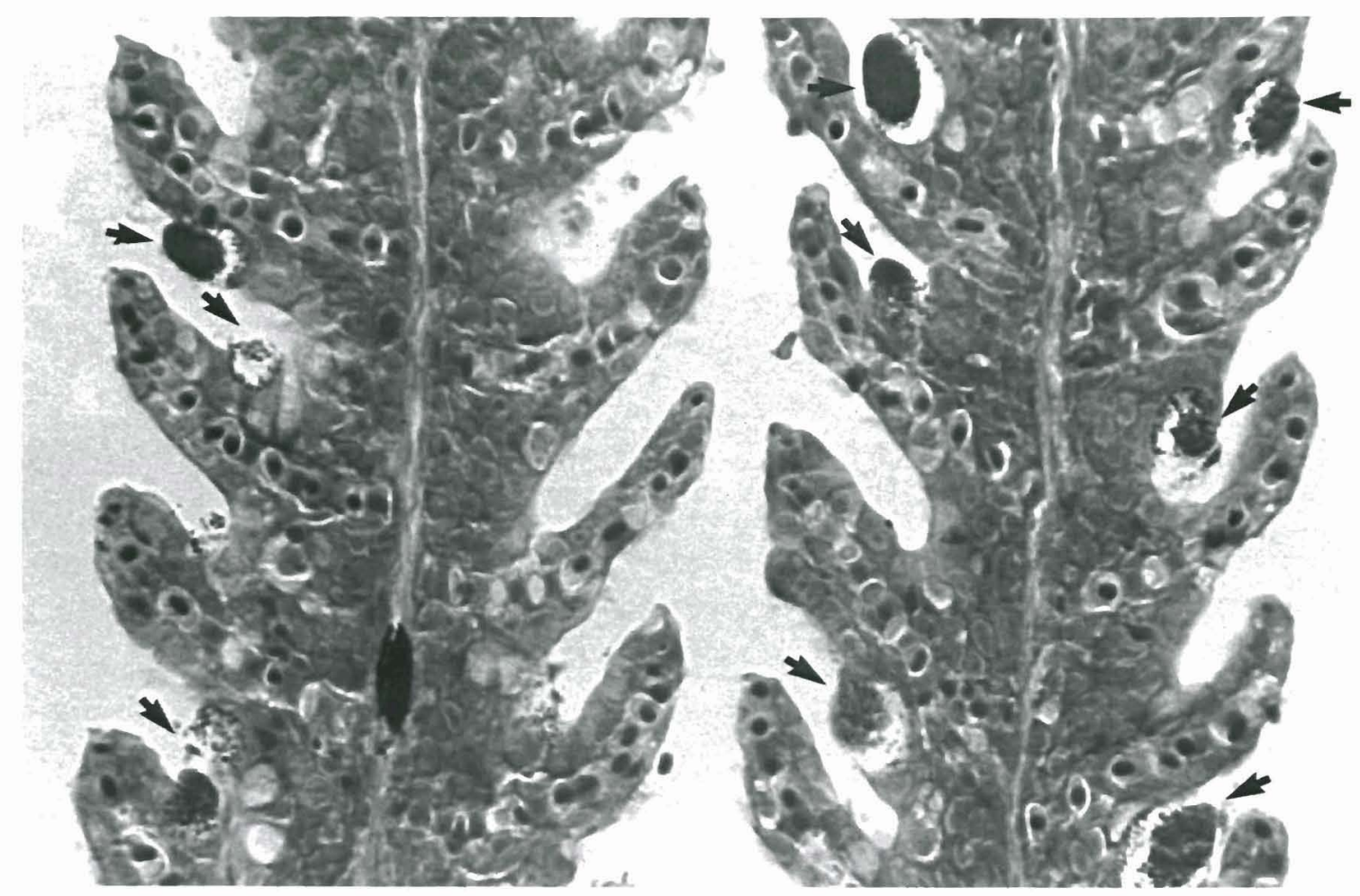

Fig. 1. Salvelinus namaycush. Epitheliocystis-infected gill of lake trout from Hatchery A. Numerous inclusions (arrows), and filament and lamellar thickening are visible. $(\times 525)$
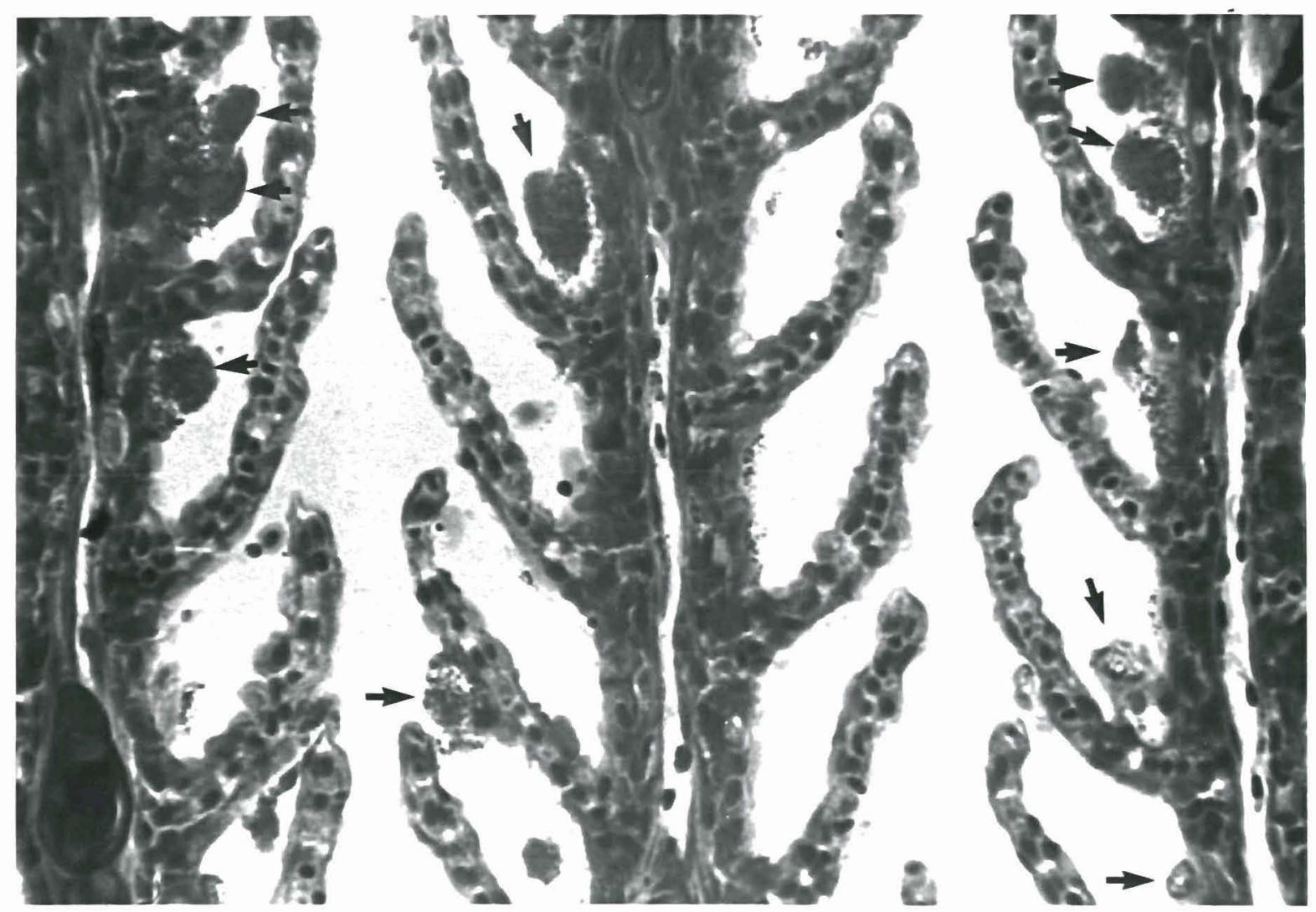

Fig. 2. Salvelinus namaycush. Epitheliocystis-infected gill of juvenile lake trout from Hatchery B. Inclusion bodies are denoted by arrows. Note differences in lamellar thickening between fish from Hatchery A (Fig. 1) and Hatchery B (this fig.) $(\times 540)$ 
was observed. The lesions associated with epitheliocystis infections were less severe in the fish at Hatchery B than at Hatchery A. Focal lesions of epithelial hypertrophy were associated with branchial inclusions (Fig. 2).

In addition to the branchial lesions, several systemic lesions (not shown) were observed consistently. These are mentioned and discussed later.

\section{Transmission electron microscopy}

Ultrastructural examination revealed that the primary causative agent implicated in the epitheliocystis infections was similar in fish at both hatcheries. The organism contained in the inclusion bodies of gills from Hatchery A and B exhibited typical chlamydial morphology and size (Figs. 3 and 4). The major stages of the chlamydial developmental cycle were present within a cytoplasmic vacuole: initial bodies (700 to $1250 \mathrm{~nm}$ ), intermediate bodies (400 to $600 \mathrm{~nm}$ ), and dumbbell-shaped dividing forms (800 to $1300 \mathrm{~nm} \times 575$ to $750 \mathrm{~nm}$ ) (Fig. 4). In addition to the normal chlamydial forms, a particle with a bleb (total length 815 to $900 \mathrm{~nm}$, oval head length 375 to $450 \mathrm{~nm}$, oval head width 250 to $300 \mathrm{~nm}$, tail diameter 80 to $115 \mathrm{~nm}$ ) resembling the head and tail cell (HTC) form described by Rourke et al. (1984) was observed. The inclusion was demarcated by a trilaminar membrane. The location of the forms within the inclusion in the gill lamellae appeared to correlate with the developmental stages. Initial bodies, intermediate bodies, and the dividing forms were generally located at the base of the inclusion, closest to the area containing cytoplasm. The HTC form was located primarily in the center and at the apex of the inclusion (Fig. 3).

Small vesicle-like particles were observed at the periphery of all inclusions adjacent to areas containing cytoplasm (Figs. 4 and 5). The vesicles consisted of a round 'head' (45 to $70 \mathrm{~nm}$ ) atop a short stalk (15 to 25 $\mathrm{nm}$ ) which projected from the cytoplasm-inclusion body interface.

A second particulate agent was observed in the branchial tissue of fish at Hatchery B but it did not exhibit typical clamydial forms. Although the agent appeared to occur in groups intracellularly, a delineating membrane forming a discrete inclusion body was not observed. Two forms of the agent were found (Fig. 6). One type contained an electron-dense nucleoid enveloped in a fine granular cytoplasm enclosed by a distinct membrane (350 to $550 \mathrm{~nm}$ ). The other form lacked a dense nucleoid and was more uniform in size (350 to $425 \mathrm{~nm}$ ). These particles shared some of the morphological features of the condensing intermediate body found in inclusion bodies; however, the coarse granular cytoplasmic constituent was absent.

\section{Immunofluorescence microscopy and isolation}

Branchial tissue sections stained with the FITC conjugated antibody specific for the chlamydia genus antigen were not positive. The inclusion bodies, which were readily identifiable by both phase and fluorescence microscopy, exhibited only a low degree of fluorescence slightly above that of the background. In contrast, inclusion bodies in formalin-fixed, positive control liver tissue from Xenopus laevis infected with Chlamydia psittaci were strongly fluorescent, and background fluorescence was minimal. Uninfected gill tissue, used as a negative control, was not fluorescent.

Isolation of the agent from the outbreaks at Hatcheries A and B was not achieved in McCoy and EPC cell lines. The EPC cell line has been demonstrated to be capable of supporting the growth of Chlamydia psittaci isolated from Xenopus laevis using standard chlamydial isolation procedures (Newcomer \& Maxwell unpubl.). Permutations of cycloheximide treatment, centrifugation of particles onto the cell line monolayer, and filtration of the inoculum did not facilitate growth of the agents.

\section{DISCUSSION}

The present study is the first report of epitheliocystis in lake trout and the second in salmonids (Rourke et al. 1984). The primary agent observed in fish at Hatcheries A and B had inclusion bodies with a delineating membrane, were in close association with the secondary lamellae, and ranged in size from 9 to $25 \mu \mathrm{m}$. The particles within inclusion bodies appeared to conform to the morphologies pathognomonic of the chlamydial life cycle. The HTC form observed within epitheliocystis inclusion bodies might be an atypical form of the elementary body, the infectious stage. Avakyan \& Popov (1984) found several aberrant morphological forms of Chlamydia psittaci and C. trachomatis during ultrastructural investigations. The low osmolarity of the freshwater environment might contribute to the evolution of an atypical elementary body form. With most chlamydia-like agents, elementary bodies are released into and transferred via body fluids. The chlamydialike agents found in branchial inclusion bodies however, are released into a medium (freshwater) containing relatively low ionic concentrations.

The small vesicle-like structures at the base of the inclusion body adjacent to cytoplasm appear similar to those described by Rourke et al. (1984). The nature of 


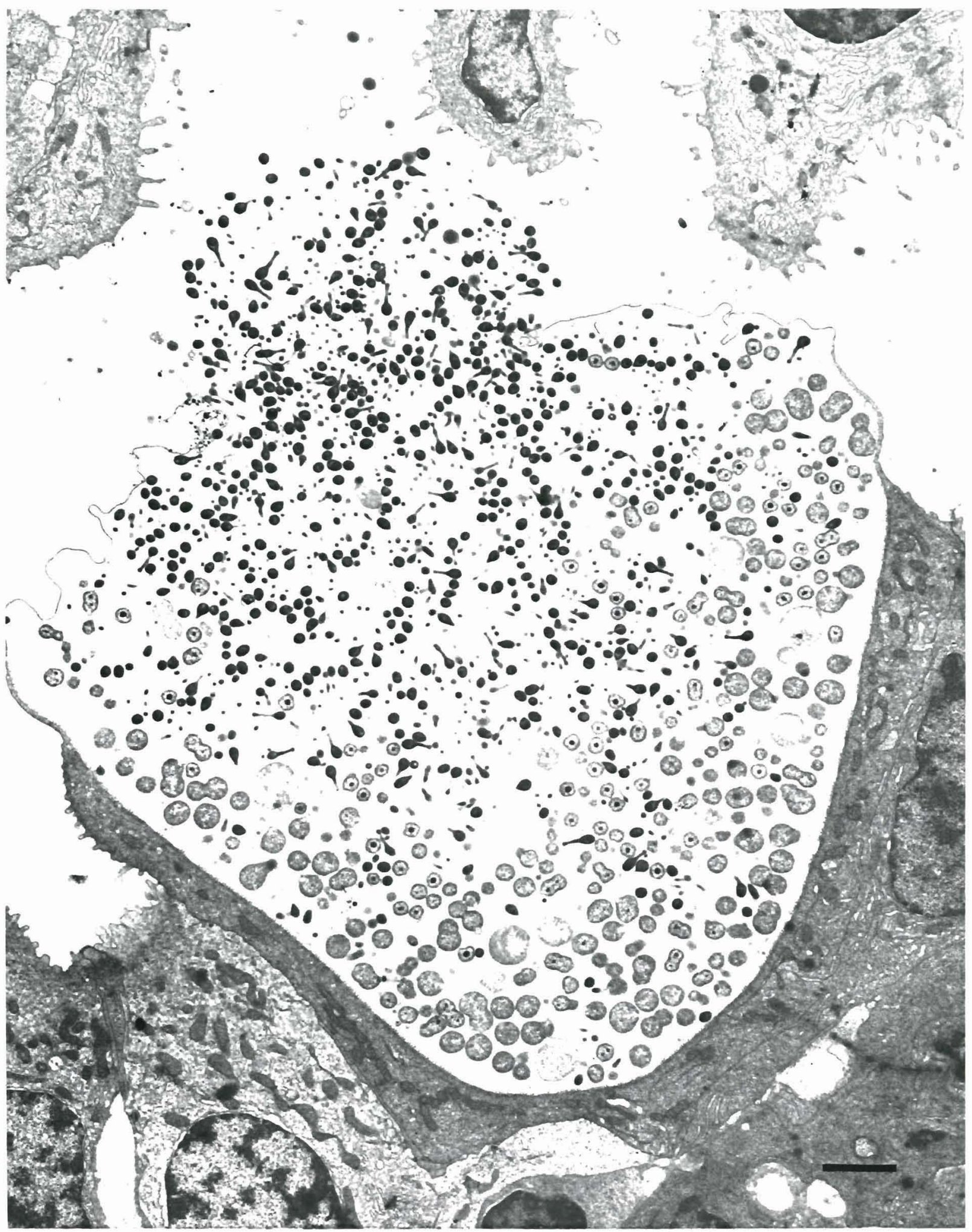

Fig. 3. Salvelinus namaycush. Membrane-bound epitheliocystis inclusion body (membrane is broken at apex) in branchial tissue of juvenile lake trout. (Bar $=1 \mu \mathrm{m})$ 


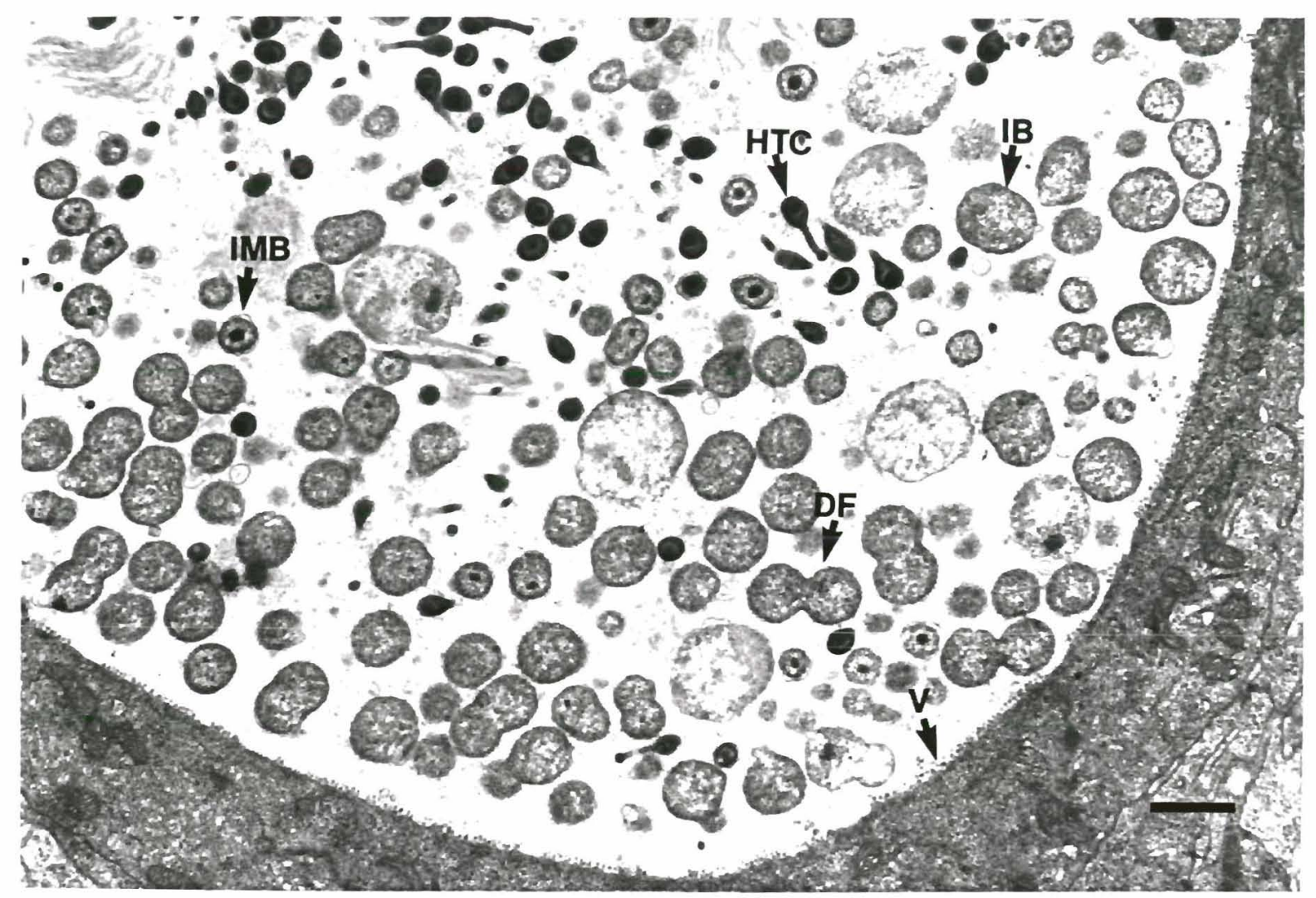

Fig. 4. Salvelinus namaycush. Higher magnification of epitheliocystis inclusion body containing characteristic chlamydial particles: initial body (IB), intermediate body (IMB) and dumbbell-shaped dividing form (DF). Head-tail cells (HTC) and small vesicles (V) also present. (Bar $=2 \mu \mathrm{m})$

these particles is unknown. One possibility is that these particles might be clathrin-coated vesicles involved in the transport of secretory products or plasma membrane proteins. The epitheliocystis-associated vesicles are within the size range of 50 to $100 \mathrm{~nm}$ generally reported for clathrin-coated vesicles.

Although branchial lesions and significant mortalities were observed in both populations of juvenile lake trout, an etiological role cannot be ascribed with certainty to the epitheliocystis agent. The systemic lesions observed in fish during epizootics, including renal glomerulitis and renal tubule degeneration, and extensive hyperplasia of epithelial cells of the skin, nares, upper palate, and alimentary tract are consonant with pathological conditions associated with several other epitheliocystis infections and with chlamydial infections in other vertebrates (Storz 1971). Miyazaki et al. (1986) observed similar renal lesions in red sea bream Pagrus major infected with epitheliocystis during an epizootic that resulted in a $20 \%$ mortality. Epithelial hypertrophy due to epitheliocystis has been documented in bluegill Lepomis macrochirus (Hoffman et al. 1969). In addition, epitheliocystis-like lesions have been observed in the pericardium of lake trout undergoing similar mortalities (C. Smith, USFWS, Bozeman, Montana, USA, pers. comm.).

Several extensive investigations of the lake trout epizootics have failed to implicate any other primary etiologic agents. F. P. Meyers (unpubl.) examined more than 26 water quality parameters including dissolved oxygen, pH, ammonia-nitrogen, nitrate-nitrogen, BOD, suspended solids, and metal concentrations and concluded that none were the primary cause of the mortalities. In addition, similar lesions observed in epizootics at 4 other lake trout hatcheries with different environmental conditions indicate that water quality is not the causative factor (Bradley \& Newcomer unpubl.). Attempts at virus isolation using standard procedures for fish viruses (AFS,FHS 1985) in our laboratory and elsewhere (Meyers unpubl., H. Jackson, USFWS, LaCrosse, Wisconsin, USA, pers. comm.) have failed to yield any known viral agents. The only bacterial pathogen detected was a Pseudomonas sp. but it appeared to be a secondary invader (R. Nelson, USFWS, LaCrosse, Wisconsin, pers. comm.). Isolation of the epitheliocystis agents and subsequent infectivity and pathogenicity studies will be required to verify that these agents have an etiological role in these epizootics. 
Fig. 5. Salvelinus namaycush. Intra-inclusion vesicles (v) at the cytoplasm-inclusion body interface. Note initial body (IB) in upper corner for size comparison. $(\mathrm{Bar}=100 \mathrm{~nm})$
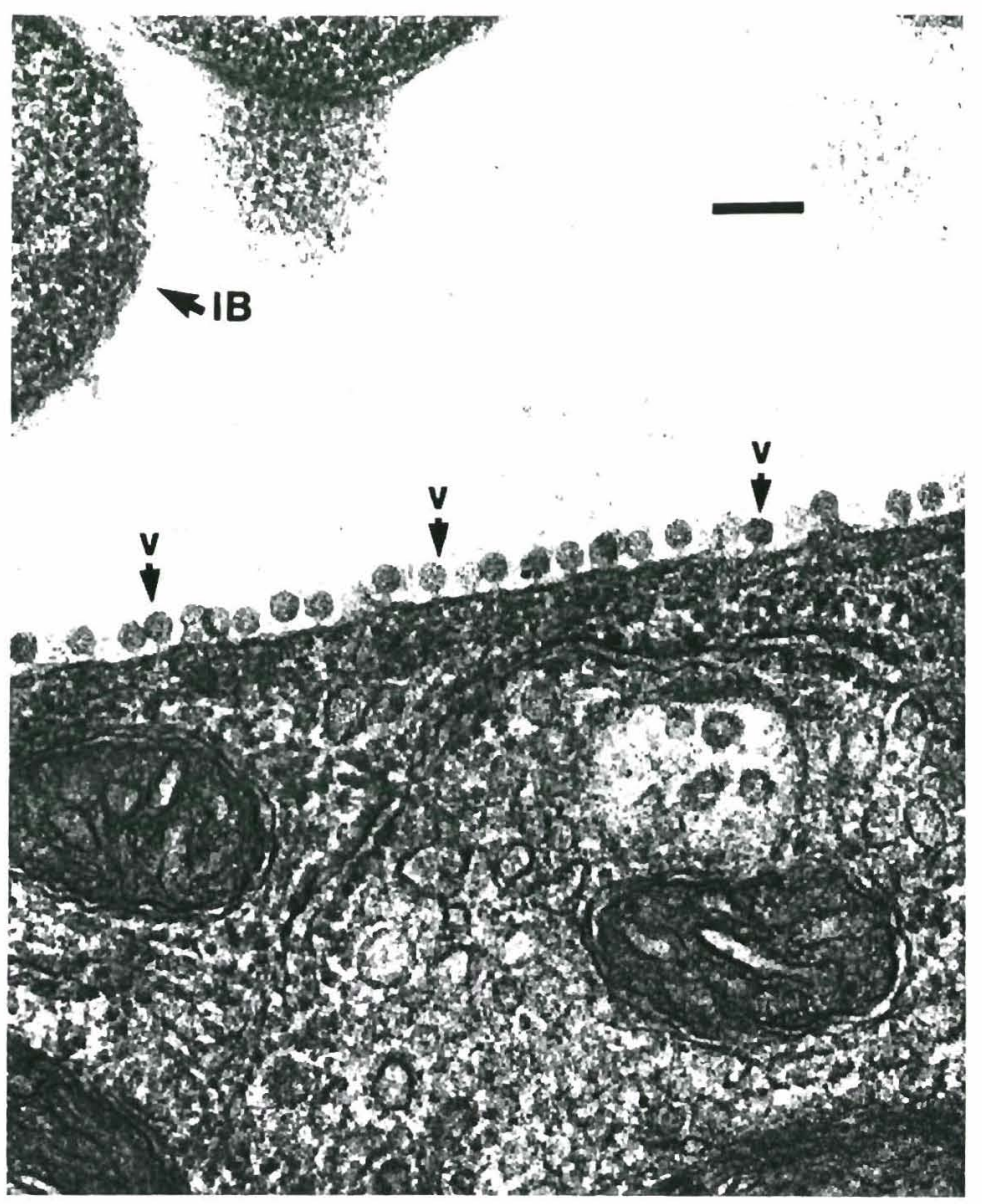

Definitive classification of the polymorphic agents of epitheliocystis is uncertain. The ultrastructural characteristics of the primary agents found in fish at Hatcheries $\mathrm{A}$ and $\mathrm{B}$ were similar to those unique to the chlamydial life cycle. Three of the 4 forms of the chlamydial developmental cycle exhibited the appropriate dimensions and shapes (Storz \& Spears 1977, Avakyan \& Popov 1984). The fourth atypical or HTC form, previously described by Rourke et al. (1984) in Salmo gairdneri, may represent an atypical elementary body form.

Although the ultrastructural evidence for classification of the agent as chlamydia is convincing, the immunofluorescent data were not supportive. All known chlamydia contain a genus-specific membrane lipopolysaccharide (Moulder 1984). Minimal or no fluorescent staining was observed when epitheliocystis-infected, formalin-fixed branchial tissue was probed with an FITC-labelled antibody to the genus-specific antigen. The effect of reprocessing formalin-fixed tissue for immunofluorescence analysis, as described, did not eliminate the immunoreactivity of chlamydial antigen in Xenopus laevis liver. We have not been successful in producing formalin-fixed branchial tissue infected with Chlamydia psittaci as a positive control (Newcomer \& Bradley unpubl.). Thus we are unable to conclude whether fish gill tissue suppresses an otherwise possible fluorescence.

The ultrastructure of the second agent from fish at Hatchery B does not resemble the typical chlamydialike forms. Only 2 forms were observed, a semi-condensed particle and a larger particle with a central nucleoid. The semi-condensed form lacking a nucleoid might be an artifact due to sectioning rather than an actual pleiomorphic stage. In addition, the lack of a definitive membrane bound inclusion body precludes the classification of the agent as Chlamydia spp. Immunofluorescent examination demonstrated that the agent lacked the genus-specific antigen also. The significance, if any, of this agent in epitheliocystis infections is unknown.

Our failure to isolate the epitheliocystis agent may have been due primarily to the difficulty in obtaining known positive samples in 'good condition'. However, it might also indicate that the systems utilized are unacceptable for culture of these agents.

The primary epitheliocystis agent infecting juvenile lake trout during the epizootics is similar to that 


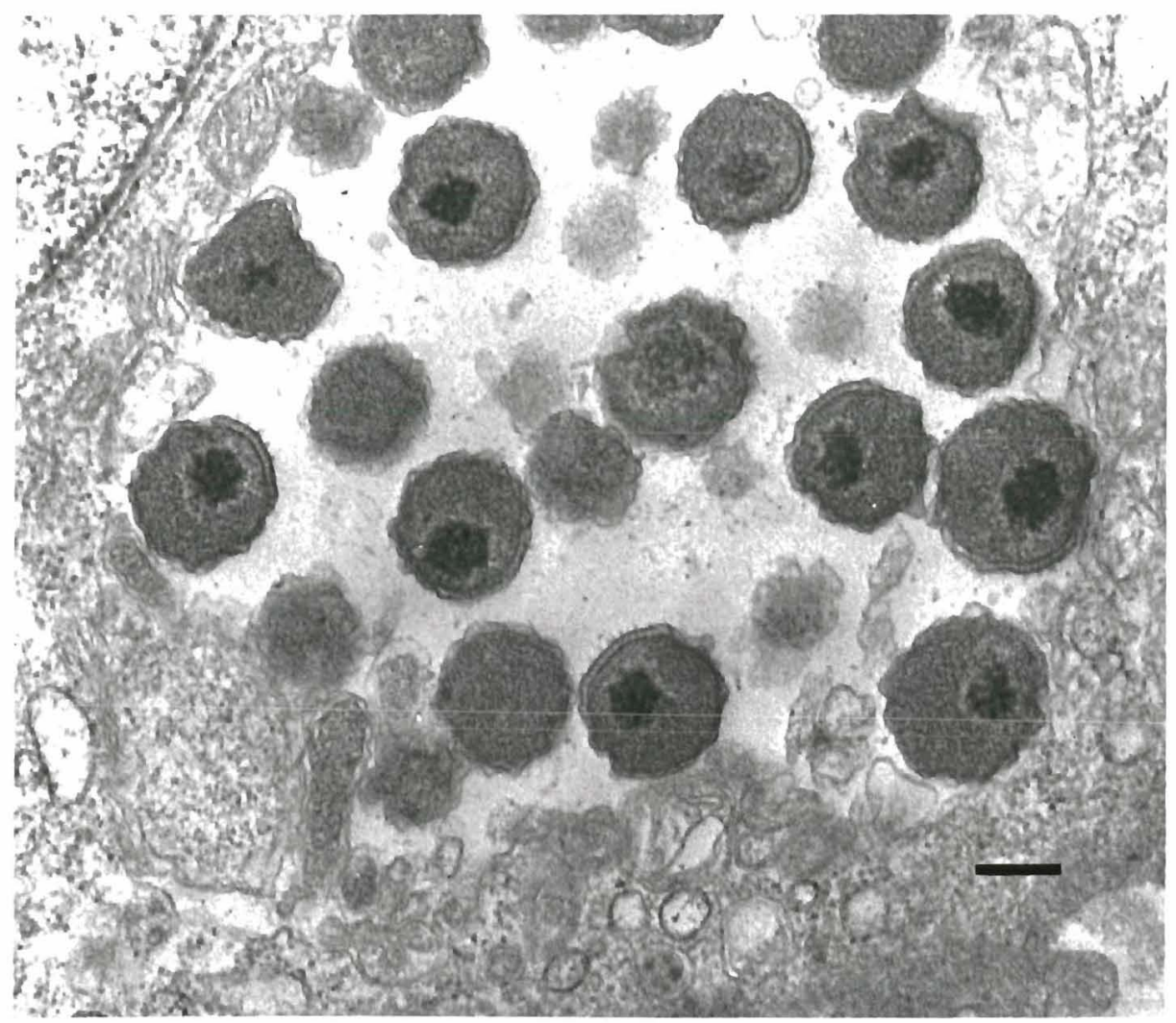

Fig. 6. Secondary agent found in branchial tissue of lake trout at Hatchery B. $($ Bar $=250 \mathrm{~nm})$

observed by Rourke et al. (1984) in steelhead trout. Thus, this agent appears capable of intergeneric infection. The ultrastructural characteristics indicate that this agent may be a true chlamydia or a 'protochlamydia' lacking the genus-specific antigen. Additional research - specifically, isolation and culture, ultrastructural and biochemical characterization, and antibiotic resistance - are necessary prior to definitive taxonomic classification of the agent.

\section{NOTE ADDED IN PROOF}

Since the submission of this article, we have isolated a previously undescribed fish virus which we have recently demonstrated to be the primary etiologic agent of the lake trout epizootics.

Acknowledgements. The authors thank Ms Sheila Polofsky for preparation of histological samples and Dr R. E. Wolke for critical review of the manuscript. Ms M. Mann is acknowledged for preparation of the manuscript. This project was supported in part by BRSG 2 S07 RR07047-2 and by NIH RR01046 awarded by the Division of Research, Resources, National Institutes of Health. T.M.B. was partially supported by an URI Summer Faculty Fellowship. This is R I Agricultural Experiment Station Contribution No. 2365.

\section{LITERATURE CITED}

American Fisheries Society, Fish Health Section (1985). Procedures for the detection and identification of certain fish pathogens. Amos, K. H. (ed.) Washington, D.C.

Avakyan, A. A., Popov, V. L. (1984). Rickettsiaceae and Chlamydiaceae: comparative electron microscopic studies. Acta Virol. 28: 159-173

Hoffman, G. L., Dunbar, C. E., Wolf, K., Zwillenberg, L. O. (1969). Epitheliocystis, a new infectious disease of the bluegill (Lepomis macrochirus). Antonie van Leenwenhoek. Microbiol. Serol. 35: 146-158

Karnovsky, M. J. (1965). A formaldehyde-glutaraldehyde fixative of high osmolarity for use in electron microscopy. J. Cell Biol. 27: $137 \mathrm{~A}$

Miyazaki, T., Fujimaki, Y., Hatai, K. (1986). A light and electron microscopic study on epitheliocystis disease in cultured fishes. Bull. Jap. Soc. scient. Fish. 52: 199-202

Molnar, K., Boros, G. (1981). A light and electron microscopic study of the agent of carp mucophilosis. J. Fish Dis. 4: 325-334

Morrison, C., Shum, G. (1983). Epitheliocystis in American plaice, Hippoglossoides platessoides (Fabricus). J. Fish Dis. 6: 303-308

Moulder, J. W. (1984). Looking at chlamydiae without looking at their hosts. Am. Soc. Microbiol. 50: 353-362

Olufemi, B. E. (1986). Application of the fluorescent antibody technique (FAT) to the demonstration of Aspergillus organisms in formalin-fixed tissues of tilapias. J. Fish Dis. 9: 91-93

Paperna, I. (1977). Epitheliocystis infection in wild and cultured sea bream (Sparus aurata Sparidae) and grey mullets (Liza ramada, Mugilidae). Aquaculture 10: 169-176 
Paperna, I., Alves DeMatos, A. P. (1984). The developmental cycle of epitheliocystis in carp, Cyprinus carpio L. J. Fish Dis. 7: $137-147$

Paperna, I., Laurencin, F. B. (1979). Parasitic infections of sea bass, Dicentrarchus labrax, and gilt head sea bream, Sparus aurata, in mariculture facilities in France. Aquaculture 16: 173-175

Paperna, I., Sabnai, I. (1980). Epitheliocystis disease in fish. Ahne, W. (ed.) Fish diseases, Third COPRAQ-Session. Springer Verlag, Berlin, p. 228-234

Paperna, I., Sabnai, I., Castel, M. (1978). Ultrastructural study of epitheliocystis organisms from gill epithelium of the fish Sparus aurata (L.) and Liza ramada (Risso) and their relation to the host cell. J. Fish. Dis. 1: 181-189

Paperna, I., Sabnai, I., Zachary, A. (1981). Ultrastructural studies in piscine epitheliocystis: evidence for a pleomorphic developmental cycle. J. Fish. Dis. 4: 459-472

Reynolds, E. S. (1963). The use of lead citrate at high $\mathrm{pH}$ as an electron-opaque stain in electron microscopy. J. Cell Biol. 17: 208-212

Ripa, K. T., March, P. A. (1977). New simplified culture technique for Chlamydia trachomatis. In: Holmes, K. K., Hobson, D. (eds.) Non-gonococcal urethritis and related infections. Am. Soc. Microbiol., Washington, D.C., p. 323-327

Rourke, A. W., Davis, R. W., Bradley, T. M. (1984). A light and electron microscopic study of epitheliocystis in juvenile steelhead trout, Salmo gairdneri Richardson. J. Fish Dis. 7: 301-309

Spencer, W. N., Johnson, F. W. A. (1983). Simple transport medium for the isolation of Chlamydia psittaci from clinical material. Vet. Rec. 113: 535-536

Spurr, A. R. (1969). A low viscosity epoxy resin embedding medium for electron microscopy. J. ultrastruc. Res. 26: $31-43$

Storz, J. (1971). Chlamydia and chlamydia-induced diseases. Charles C. Thomas, Springfield, Illinois

Storz, J., Spears, P. (1977). Chlamydiales: properties, cycle of development and effect on eukaryotic host cells. Curr. Top. Microbiol. Immunol. 76: 167-212

Swoveland, P. T., Johnson, K. P. (1979). Enhancement of fluorescent antibody staining of viral antigens in formalinfixed tissues by trypsin digestion. J. infect. Dis. 140: $758-764$

Wilcke, B. W. Jr., Newcomer, C. E., Anver, M. R., Simmons, J. L., Nase, G. W. (1983). Isolation of Chlamydia psittaci from naturally infected African clawed frogs (Xenopus laevis). Infect. Immun. 41: 789-794

Wolke, R. E., Wyand, D. S., Khairallah, L. H. (1970). A light and electron microscopic study of epitheliocystis disease in the gills of Connecticut striped bass (Morone saxatilis) and white perch (Morone americanus). J. Comp. Path. 80: 559-563

Zachery, A., Paperna, I. (1977). Epitheliocystis disease in the striped bass, Morone saxatilis from the Chesapeake Bay. Can. J. Microbiol. 23: 1404-1414

Zimmer, M. A., Ewing, M. S., Kocan, K. M. (1984). Epitheliocystis disease in the channel catfish, Ictalurus punctatus (Rafinesque). J. Fish Dis. 7: 407-410 